The New Zealand case is somewhat different again. The committee there has decided that "excluding whole treatments, services or diagnostic categories is arbitrary and does not have the capacity to tailor services according to the needs of individuals." ${ }^{4}$ It has developed a four point framework, however, for making decisions about allocating resources. The four criteria are that treatment or service should provide benefit and value for money, that it should represent a fair use of resources, and that it should be consistent with community values. The committee's main work, however, has consisted in developing consensus among the medical profession about the desirability of particular forms of treatment and generating public debate about such issues as whether social factors should play any part in deciding priorities in the treatment of individual patients. Like the Dunning committee it has proposed that there should be explicit national criteria for determining the need for non-urgent surgery and diagnostic procedures-replacing waiting lists by "booked admissions." Unlike the Dunning committee, whose life ended with the publication of its report, the New Zealand body is implementing its own recommendation in cooperation with the medical profession.

What conclusions can be drawn from this international experience? Firstly, drawing up a set of principles is extraordinarily difficult. There is little cross national consensus: contrast Sweden's rejection of a cost-benefit approach with New Zealand's use of the value for money criterion. Secondly, where agreement exists it tends to be about the easy options: thus everyone is agreed that ineffective treatment should not be offered. Thirdly, the devil lies in translating general principles into practice, particularly when it comes to the treatment of individual patients. There is a case, therefore, for pragmatism-that is, for distilling general rules from practice rather than imposing a set of principles on practice.

Accepting such a conclusion does not, however, imply grounds for self congratulatory complacency in Britain, for Britain's pragmatism is half baked. There has been no systematic attempt to draw out, let alone codify, the implica- tions of practice in the setting of priorities: to examine, for example, the assumptions about the allocation of resources implicit in clinical guidelines. Here the example of New Zealand is instructive. The Swedish parliamentary commission and the Dunning committee were one off exercises. Once the tablets of stone were delivered, work stopped. In contrast, the New Zealand core services committee is engaged in a continuing process of dialogue with doctors and the public. Priorities and criteria for rationing emerge from this process.

It is difficult to know just how effective the New Zealand committee has been in influencing public policy or medical practice and whether such a model would survive transplantation into the very different environment of the NHS. Nevertheless, the New Zealand experience strongly supports the recommendations of the Royal College of Physicians that a National Council for Health Care Priorities be established "to identify all the relevant issues, analyse them publicly and comprehensively, and satisfy all interested parties that their views are being considered" (p 767).5 ${ }^{56}$ Precisely because there is no way of resolving this question once and for all-because changing medical technology and shifting social attitudes will always create new dilemmas of choicethere is all the more reason for institutionalising what is bound to be a continuing debate.

RUDOLF KLEIN

Centre for the Analysis of Social Policy,

University of Bath,

Bath BA2 7AY

1 Government Committee on Choices in Health Care. Report. Rijswijk, Netherlands: Ministry of Welfare, Health and Cultural Affairs, 1992.

2 Cumming J. Core services and priority-setting: the New Zealand experience. Health Policy 1994;29:41-60.

3 Swedish Parliamentary Priorities Commission. Priorities in health care. Stockholm: Ministry of Health and Social Affairs, 1995.

4 National Advisory Committee on Core Health and Disability Support Services. Third report: core services for 1995/96. Wellington: Core Services Committee, 1994.

5 Setting priorities in the NHS: a framework for decision-making. London: Royal College of Physicians, 1995.

6 Smith J. Royal college calls for national priority setting. BMF 1995;311:767.

\title{
Emergency contraception
}

\section{Time to loosen medical controls over its availability}

Emergency hormonal contraception is well established in the form of the Yuzpe regimen. ${ }^{1}$ This comprises $100 \mu \mathrm{g}$ ethinyloestradiol and $1 \mathrm{mg}$ levonorgestrel given in two doses 12 hours apart. The first dose must be given within 72 hours of the unprotected intercourse or failure of contraception. At present only one medicinal product (PC4) is licensed for the purpose (although an alternative is four tablets of the combined oral contraceptive ethinyloestradiol $50 \mu \mathrm{g}$ and levonorgestrel $250 \mu \mathrm{g}$ (Ovran)), and may be obtained only on prescription from general practitioners, family planning clinics, and some accident and emergency departments. But a growing number of doctors would like emergency contraception to be made more widely available, recognising that it could do much to reduce the abortion rate among teenagers. ${ }^{2}$ Acting before implantation, the method does not constitute abortion under the terms of present legislation.

Studies suggest that three out of four potential pregnancies are prevented by emergency hormonal contraception. ${ }^{3} \mathrm{~A}$ strong belief persists, not only among potential users but also among doctors, ${ }^{4}$ that such contraception is medically unsafe and should be prescribed with great care. One hundred micrograms of ethinyloestradiol is perceived as a high dose of oestrogen, with all its expected risks-but only five adverse vascular reactions in association with the Yuzpe regimen have been reported to the Medicines Control Agency over the past 10 years. ${ }^{5}$ When drawing up guidelines, the clinical and scientific committee of the Faculty of Family Planning found few contraindications to its use. ${ }^{6}$ Suspected pregnancy is an absolute contraindication, as is migraine at the time of presentation in a woman with a history of focal migraine.

Patients who are immobile, have known abnormalities of clotting factors, or have a history of thromboembolic disease have a theoretically increased risk, but this should be weighed against the known risks of pregnancy. When the Yuzpe regimen was introduced an increased risk of ectopic pregnancy was feared but only one case has been reported, in a woman with tubal disease. ${ }^{7}$ Breast feeding is a relative contraindication until feeding is established.

Should we be anxious about repeated use of emergency hormonal contraception? Three episodes of use in a single cycle would still be equivalent only to a packet of a modern low dose combined pill. Nausea is common, and it seems 
unlikely that women would "overdose" on hormones. Because $2-3 \%$ of women using emergency hormonal contraception will become pregnant fears have been raised about teratogenicity. Evidence suggests that these steroids taken before implantation do not affect fetal development, ${ }^{8}$ but little is known about their effects if pregnancy is already established.

Given that emergency hormonal contraception seems an effective treatment that may be used safely in all but a very few situations, why should it not be more widely available? There are several ways in which this could be achieved. Nurses trained in family planning could prescribe emergency contraception. High street pharmacies offer even greater accessibility, which is why a change of category from prescription only to pharmacy has been proposed.

Ready access to the product would not mean that couples would be denied sympathetic professional advice and follow up if they wanted them. Certainly, potential users need to be well informed, ${ }^{910}$ and a recent health education campaign has been launched to improve public knowledge. But even the simplest means of spreading information may be blocked by fears about legal and ethical implications. ${ }^{11}$ Studies are under way to determine whether increasing the accessibility of emergency contraception reduces the incidence of unplanned pregnancy. As evidence gathers it will be hard to see why we need to exert so much medical control.

JEANETTE CAYLEY

Women's Services,

Featherstone Road Clinic,

Southall UB2 5BQ

1 Yuzpe AA, Lancee WJ. Ethinyl estradiol and dl-norgestrel as a postcoital contraceptive. Fertil Steril 1977;28:932-6.

2 Drife JO. Deregulating emergency contraception. BMF 1993;307:695-6.

3 Trusseli J, Stewart F. The effectiveness of postcoital hormonal contraception. Fam Plann Perspect 1992;24:262-4.

Webb A, Morris J. Practice of postcoital hormonal contraception-the results of a national survey. Brf Family Planning 1993;18:113-8.

5 Paintin D, ed. The provision of emergency contraception. London: Royal College of Obstetricians and Gynaecologists Press, 1995.

6 Kubba A A. Emergency contraception-guidelines for doctors. London: Faculty of Family Planning and Reproductive Health Care of the Royal College of Obstetricians and Gynaecologists, 1995.

7 Kubba A A, Guillebaud J. Case of ectopic pregnancy after postcoital contraception with ethinyloestradiol-levonorgestrel. BMF 1983;287:1343-4.

8 Cardy G. Work in progress - a survey of pregnancies after failed coital contraception. Br $\mathcal{G}$ Family Planning (in press).

9 Whitlow BJ, Desmond N, Hay P. Pregnant teenagers and contraception. BMF 1995;311:806.

10 Randall S, Lewis C. Pregnant teenagers and contraception. BMF 1995;311:807.

11 Bromham D. Contraception. In: Clements $\mathrm{R}$, ed. Safe practice in obstetrics and gynaecology. A medicolegal handbook. Edinburgh: Churchill Livingstone, 1994:381-95.

\section{Angiotensin converting enzyme genotypes and disease}

\section{Conflicting results from research leave the picture unclear}

Ischaemic heart disease has both environmental and genetic influences, but research has concentrated on the environmental angle. The main modifiable risk factors have been identified and preventive measures introduced with substantial success. Our knowledge of genetic factors has yet to be established in the same ways. The idea of routine tests evaluating genetic risk factors seems appealing but it has not been feasible. Test results could not at present provide a clinician with more than confirmation of a positive family history as an indicator of increased susceptibility to the disease.

The picture has changed with recent reports that a genotype of the angiotensin converting enzyme (ACE) gene may be a risk factor for ischaemic heart disease. ${ }^{12}$ These studies show the potential of modern molecular biology as a research tool for establishing genetic risk factors for cardiovascular diseases. Moreover, in this case a treatment-angiotensin converting enzyme inhibition-is available and may prove useful for those at risk. As yet, however, the predictive utility of the data from genetic and epidemiological studies remains uncertain.

A report in Nature by Cambien et al first raised the possibility of an association between ACE gene polymorphism and increased risk for myocardial infarction in relatively homogeneous groups of French and Irish men. This was a retrospective case control comparison of men studied three to nine months after acute myocardial infarction. ${ }^{1}$ The gene polymorphism is due to the presence (insertion or $\mathrm{I}$ ) or absence (deletion or $\mathrm{D}$ ) of a 287 base pair sequence in a noncoding section of the ACE gene. The DD genotype was found in $32.3 \%$ of patients and $27 \cdot 3 \%$ of controls and was associated. with a $34 \%$ (adjusted odds ratio 1.34) excess risk for acute myocardial infarction when compared with that for patients with the other two genotypes ID and II. The association seemed particularly strong in a subgroup with an overall low risk from conventional factors (adjusted odds ratio $3 \cdot 2$ ). The DD genotype was also associated with higher mean plasma concentrations of angiotensin converting enzyme- suggesting that the increased risk from this genotype may result from raised concentrations of angiotensin converting enzyme and associated higher concentrations of angiotensin II.

The hypothesis that this genetic variation of the ACE locus could be associated with an increased risk for acute myocardial infarction was further strengthened by the observation made by the same authors of an apparent excess of both DD and ID genotypes among those having a parental history of acute myocardial infarction. ${ }^{2}$ The higher prevalence of the DD genotype or $\mathrm{D}$ allele in patients with diabetes and coronary heart disease, ${ }^{3}$ patients with hypertrophic cardiomyòpathy experiencing sudden death from cardiac causes, ${ }^{4}$ and patients with left ventricular hypertrophy ${ }^{5}$ and ischaemic and idiopathic dilated cardiomyopathy ${ }^{6}$ suggests that the $\mathrm{D}$ allele may play a part in the pathogenesis.

Unfortunately, some other studies have not confirmed the association between the DD genotype and ischaemic heart disease. $^{7-9}$ Bohn et al studied 185 men and 49 women, survivors of acute myocardial infarction, $2 \cdot 7$ years after the event. They compared the frequency of the DD genotype in this group with that of 366 controls $^{7}$ and found that it was present less often among men patients $(23 \%)$ than controls ( $35 \%$ ), but they found no difference between women patients (31\%) and controls (29\%). ${ }^{7}$ Miettinen et al found no association between ACE gene polymorphism and the risk of premature coronary heart disease. ${ }^{8}$ The frequency of DD genotype in their study was $27 \%$ in patients and $18 \%$ in controls.

The conflict between Cambien's initial report and these later studies may be explained by chance because of small sample sizes; biases in selection of subjects or controls, or both; preferential loss of DD individuals in those who have died; or differences in genetic environmental interactions, but the inconsistencies raise doubts about the predictive utility of this genotype as a risk factor for ischaemic heart disease.

These doubts have been reinforced by a recent prospective study on 1250 men with ischaemic heart disease matched with 2340 controls from the physicians' health study of 22071 men, mostly white American physicians. ${ }^{9}$ The researchers 